\title{
A poesia brasileira e a Segunda Guerra Mundial
}

Betina Bischof ${ }^{I}$

C6 A verdadeira poesia interioriza a história". O trecho, extraído por Murilo Marcondes de um ensaio de Starobinski, condensa um dos principais pontos contemplados pelo exercício crítico em $O$ mundo sitiado: a relação entre a interioridade da voz lírica e o amplo contexto da guerra. Pode-se dizer que o livro busca precisamente elucidar o modo como a poesia incorpora em si a matéria da realidade, procurando, ao longo das análises dedicadas a cada um dos poetas, compreender como se articulam história e forma estética. Trata-se, assim, de mapear em toda a sua complexidade a relação entre contexto e expressão poética, ou, restringindo o foco, entre a dimensão da violência da guerra e o modo como cada poeta construiu sua resposta ao evento.

As dificuldades que o objeto em pauta impõe ao exercício crítico são muitas: se o que se estuda é a relação entre poesia e guerra, é inegável que o foco, voltado (com exceção do primeiro capítulo) não para poetas localizados no centro do conflito, mas para aqueles que escreveram sobre a guerra a partir de um lugar periférico, terá de enfrentar a complexidade dessa singular participação a distância nos eventos do tempo presente. Que o estudo desses poetas (Drummond, Oswald de Andrade, Cecília Meireles e Murilo Mendes) seja precedido de uma reflexão sobre poetas inseridos numa situação diametralmente oposta (poetas soldados, que participaram das trincheiras da Primeira Guerra Mundial e - em alguns casos - ali escreveram seus poemas sobre o evento) dá testemunho do terreno acidentado e muito amplo que o livro enfrenta. O objeto duplo implica também estudar as relações de experiência (Primeira Guerra) e forma vanguardista e, nos ensaios dedicados a Drummond, Oswald, Cecília e Murilo Mendes, voltar-se a uma poética e forma modernas em sua articulação com a Segunda Guerra.

É da imbricação desses dois caminhos, aliás, que parece surgir o vínculo, sugerido por Murilo Marcondes, entre Apollinaire e Drummond, a partir da citação explícita ao primeiro, em "Consideração do poema", no livro $A$ rosa do povo (1945). Não haveria poema mais adequado para essa homenagem, afirma o crítico. Por quê? O sentimento do mundo (que envolve, no livro de 1945, confiança nas possibilidades da poesia, abertura a outras fronteiras, ampliação do canto), deve ter como complemento o sentimento da forma (e aqui as contribuições de Apollinaire precisamente às inovações formais seriam uma referência forte - entre outros pontos também abordados -, cuja importância o verso/ homenagem sublinha). Assim, quando, depois de muitas páginas de análises aclaradoras sobre Ungaretti, sobre Apollinaire, sobre Owen, o foco do livro volta-se a Drummond ("Me perco em Apollinaire"), as implicações desse verso tomam corpo, armando-se em espaço de reverberações ainda não estudadas pela crítica drummondiana e com poder 
iluminador também em relação a outros poemas do livro.

Também outra das características centrais do livro $A$ rosa do povo - sua oscilação entre autonomia e abertura da palavra - encontraria eco em Apollinaire, cuja poesia, defende Murilo Marcondes, hesita igualmente (guardadas as diferenças) entre o fechamento sobre seus próprios princípios e a concomitante abertura ao acontecimento histórico. O tema é recorrente ao longo de todo o livro, que se deixa muitas vezes ler não como uma reunião de estudos mais ou menos autônomos sobre cada um dos poetas em sua relação com a guerra, mas, principalmente, como uma série de estudos atravessada pelas mesmas - e insistentes - perguntas.

Avançando, vemos que, se o crítico de um lado lê "Consideração do poema" como é corrente na fortuna crítica (o poema seria autorreflexivo, metalinguístico), ele parece privilegiar, um tanto a contrapelo daquelas interpretações, o foco que vincula a forma ao "tempo presente" (que é, neste caso e a partir dessa perspectiva, tempo de guerra). Isto é, haveria uma correspondência entre o sentimento do mundo (mas mundo em guerra) e um sentimento da forma, que aquele universo suscita. Por essa via, a articulação dos versos e materiais nos poemas voltados à guerra não se faz apenas tendo o conflito por tema, mas também deixando-se atravessar (e modificar) pelos desdobramentos e implicações da violência e embate planetários.

Dito isso, é preciso pontuar que, no interior da obra de cada um dos poetas estudados, a começar por Drummond, a relação entre expressão lírica e seu tema não se mantém estável durante os anos de Guerra. A leitura feita por Murilo
Marcondes dos poemas sobre o conflito, no livro A rosa do povo, mapeia as transformações de postura, tom e forma vividas por Drummond ao longo dos anos (1942 a 1945) em que o livro foi escrito (intervalo que é igualmente - mostra o crítico - o tempo exato de escrita dos cinco poemas diretamente relacionados à guerra no livro, como se também do ponto de vista do tempo de escrita o conflito atravessasse a coletânea como um todo).

Assim, Murilo Marcondes nos faz ver a dicção muito ponderada com que Drummond comenta o lugar do poeta face à guerra, num prefácio ao livro de Abgar Renault voltado ao tema: esse poeta, "resistindo à pressão de todas as forças desmoralizadoras, chamem-se fascismo ou qualquer outro nome [...] é um guia firme, que dá gosto seguir. Ele nos salva das pequenas e grandes confusões do momento, nos tira a perplexidade, varre de nós ao mesmo tempo o otimismo e pessimismo circunstancias". Comparando o tom equilibrado e sóbrio desse prefácio aos versos de "Carta a Stalingrado" (com dicção diametralmente oposta), Murilo se pergunta se a significativa transformação da expressão de Drummond, atravessada na "Carta..." por pathos intenso e dilatado, não teria se dado em função do embate mesmo com o fato, com a história, ou, visto de modo mais rente, como resposta a Stalingrado e a sua resistência. A sua hipótese caminha nessa direção. Poética, juízos, posicionamentos, ritmos, imagens, adesão aos fatos teriam se dobrado à experiência avassaladora do evento: a loucura da cidade, afirma o crítico na análise minuciosa e iluminadora, passa a ser também a loucura desse sujeito.

A poesia se expande, assim, em $A$ 
rosa do povo, defende Murilo Marcondes (mesmo se se levar em conta o conjunto de poemas mais escurecidos voltados à desconfiança frente ao poetar, com presença também marcante ali), porque haveria no livro uma "poesia de amplo respiro, fundamentada na aproximação mais estrita entre consciência política e consciência da linguagem".

Em $O$ mundo sitiado, à expansão do canto drummondiano parece corresponder, por sua vez, uma expansão dos recursos utilizados pelo crítico, como se ele também devesse alargar seus domínios para dar conta da complexa realidade (tocada pela dimensão planetária da guerra e de seu pathos). Assim, face a outro dos poemas de Drummond sobre a guerra, "Visão 1944", verifica-se uma ampliação das ferramentas de análise, que passam a incorporar também a comparação com as outras artes: ou, mais especificamente, a comparação dos versos do poema com a pintura de Goya e com os fotoepigramas de Brecht.

É notável o modo como Murilo Marcondes de Moura costura as implicações sem número contidas nas gravuras de Goya, numa espécie de acumulação de material que depois passará a incidir também sobre o poema de Drummond (mesmo que indiretamente. O crítico submete os seus objetos a um verdadeiro esquadrinhamento; nada pode ficar no escuro e com isso a crítica se dilata, enormemente, movendo-se para direções e esferas muito variadas da realidade e da obra. Em relação a "Visão 1944", a aproximação com Brecht é igualmente profícua; também nessa análise (como em outras), o texto se volta ao esforço de aclaramento dos muitos aspectos envolvidos na confecção das quadras (poesia) justapostas às fotografias de Guerra: a correspondência Brecht-Benjamin (e a possível influência das reflexões benjaminianas sobre o trabalho do poeta); o funcionamento da intervenção (sobre a imagem/fotografia) e semelhança disso com a montagem; o "poder de desmascaramento" da forma antiga (epigrama) frente ao contexto da guerra moderna etc. A aproximação desse material (os 69 fotoepigramas) às quadras de "Visão 1944" teria sido motivada pelo "mosaico" que ambos os trabalhos (poema e fotoepigramas) compõem (trabalho levado a cabo por Drummond, lembra-nos Murilo Marcondes, pela via tão somente da palavra).

Aqui já se pode notar algo do procedimento comparativo do livro, que vai muito além de apontar semelhanças. Evitando aproximar as artes a partir da mera similitude de tema ou motivo específico, a comparação, na verdade, parece antes fecundar os dois lados da equação, para então criar não uma sobreposição, mas antes uma espécie de campo imantado entre os dois objetos. É nesse campo imantado que se movimenta a crítica, articulando poesia e gravura, poesia e fotografia, poesia e música.

Se a dicotomia entre evento planetário e voz pessoal está presente desde as primeiras páginas de $O$ mundo sitiado, a questão retorna, com força e especificidade, no estudo da poesia de Cecília Meireles, no qual se procura compreender, precisamente, as implicações do movimento de apagamento do "mundo grande" e do deslocamento dos versos para o que é ínfimo, sem utilidade, avesso ao monumental. Haveria, nessa tendência, defende o crítico a partir de análises muito atentas à concretude e matéria do poema, um traço melancólico - mas melancolia que não se priva de um arguto 
conhecimento da realidade e que, exatamente por isso, é ativa em seu repúdio consciente do mundo. Nesse sentido, Murilo Marcondes se pergunta pelo significado que tem a abertura do lirismo delicado de Cecília Meireles à Segunda Guerra Mundial. É de um espaço recolhido, intimo, privado e bucólico - pontua - que ela abordará o conflito. Em sua poesia teria lugar, desse modo, a mistura bastante singular entre o recuo em relação ao mundo e uma atitude internacionalista.

Ainda procurando elucidar o ponto de vista do sujeito lírico na poesia de Cecília Meireles, Murilo vê um outro aspecto da sua indisposição com o mundo: o incômodo seria também gerador de poesia, além de ser, justamente em seu recolhimento, profundamente político. Assim, o recuo do eu em relação ao mundo teria como consequência apontar criticamente, nesse mundo, o "cruel pragmatismo da realidade".

Creio que é desnecessário enfatizar como a leitura das implicações dessa poesia com o conflito armado termina por iluminar aspectos da poesia de Cecília Meireles que vão muito além dos poemas mais especificamente voltados à guerra. O mesmo acontece, é preciso pontuar, com os outros poetas ao longo do livro, o que amplia muito o efeito de sua leitura e é um dos pontos a louvar, em sua composição e arquitetura. Veja-se, nesse sentido, o último capítulo de $O$ mundo sitiado, dedicado a Murilo Mendes. Talvez o que mais chame a atenção na análise que Murilo Marcondes faz dos versos desse poeta seja o modo como ali se amalgamam mito, símbolo, imagens e... a esfera objetiva de história e sociedade. A dimensão social da lírica de Murilo Mendes estaria implicada num movimento complexo: o que é social nela, defende Murilo Marcondes, seria o desejo do canto puro, do lirismo sem contaminação, num momento em que a pureza da expressão já não é viável. $\mathrm{O}$ desejo de um canto sem máculas ou a necessidade, mesma, desse canto traria implicado o contexto em relação ao qual o canto recua e do qual se quer purificar.

O ponto de vista por meio do qual se estuda a poesia de Murilo Mendes, em O mundo sitiado, talvez se deixe resumir por meio desta dicotomia: ao poeta cabe o enfrentamento do contexto adverso, a partir da própria expressão lírica. É precisamente em função desse confronto "estranho e desigual" que Murilo Marcondes diz ter escrito o capítulo sobre Murilo Mendes (ou, até mesmo, todo o livro).

Abordar a poesia de guerra de Murilo Mendes (poeta em que o conflito é o mais presente, entre os poetas brasileiros, com 60 poemas ao todo) é difícil, afirma o crítico, pelo surgimento muito oblíquo e transformado desse tema. A dificuldade estaria também na dimensão mesma da expressão lírica, a um só tempo "historicizada" e "transfiguradora". Essa dificuldade, por sua vez, parece favorecer a veia criativa do próprio autor do livro, que dá aqui rédeas soltas ao ensaio e às suas possibilidades. Assim, é bastante curioso ver que, em dado momento do capítulo sobre Murilo Mendes, o ensaísta passe a construir, ele mesmo, um novo poema (desentranhado a partir de trechos de poemas de Murilo Mendes), prestando com isso tributo à técnica da montagem, mas também deslizando para o campo da poesia, da composição... o que pensar disso?

De certo modo, o que o crítico parece pretender é dar realce ao procedimen- 
to do "fragmento explosivo", que seria o elemento mais diretamente implicado na almejada transfiguração da realidade a que se volta a poesia de Murilo Mendes. As partes assim configuradas dos poemas desenham uma espécie de grande angular; nessa abertura, e postos em circulação pela imagem que é o baixo contínuo desses fragmentos (a asfixia), surgem os correlatos que vão da doença do poeta (tuberculose) aos céus contaminados da guerra, passando ainda pela debilidade do sopro vital e decorrente entrave à configuração do poema. Na leitura de Murilo Marcondes de Moura, o que é individual estende-se também à enfermidade coletiva, implicada pela Guerra, mas também desde sempre pela Queda.

E por quê, poderia se perguntar o leitor que acompanha essa análise, não caberia aqui, paralelamente - por conta dos muitos pontos de contato entre Jorge de Lima e Murilo Mendes (o mito, a religião, a montagem, o sopro vital) -, uma leitura dos trechos de Invenção de Orfeu ou Mira-Celi em que surgem também versos diretamente vinculados à guerra? A resposta de Murilo Marcondes de Moura é reveladora do ponto de vista crítico em torno ao qual se articulam as leituras em todo o livro: faltaria a Jorge de Lima aquele que é o baixo contínuo a acompanhar os outros elementos do poema (mito, biografia, forma estética etc.), ou seja, a história. A experiência da guerra em Jorge de Lima teria sido radicalmente alegorizada, com isso perdendo as inflexões do que é atravessado pela dimensão histórica do embate. E por essa razão ele está fora do livro.

Se esse é o ponto, em Murilo Mendes a adesão ao canto que se dilata e abarca a Guerra não é também livre de fraturas. Podem-se estudar nesse sentido as ten- sões dos versos que oscilam entre refutar e abraçar as imagens da Guerra - distantes de qualquer comunicação e, em momento posterior, abertos à terrível circunstância. Pois, em dado momento, Murilo Mendes teria respondido (em sua poesia) a uma espécie de chamado. A partir de certo ponto, defende $\mathrm{Mu}^{-}$ rilo Marcondes de Moura, delicadeza e introspecção não eram mais suficientes e foi necessário o confronto com uma realidade "brutal e pública". Os passos dessa reflexão ocorrem talvez principalmente em função de um poema, "Abismo", de cujos versos muito intrincados e opacos o crítico extrai uma leitura notável em muitas frentes.

Se há o atendimento a um chamado, ele se dá no interior de uma expressão (a poesia) que Murilo Mendes entenderia, de modo algo paradoxal, como inapta à tarefa da convocação; o que, no jogo das dobradiças (e aproximações) que se armam e desarmam, ao longo de $O$ mundo sitiado, o aproxima de Drummond. Para esses poetas, pontua a leitura crítica, voltar-se ao mundo implicaria culpa e recuo, ao mesmo tempo em que a possibilidade de se manter refratário à realidade é vista como omissão. Aqui a leitura muito arguta e minuciosa do poema aprofunda um dos pontos centrais do livro: o debate em torno à confiança na poesia e seu difícil papel frente ao conflito; apesar da complexidade de sua função (ou mesmo impossibilidade de ter uma função), seria possível afirmar (defende o crítico) que a poesia é capaz não de antepor um obstáculo ou entrave à guerra e à violência, mas de "se afirmar apesar deles e, com isso, preservar um espaço de liberdade e de dignidade para o homem". O poema se organizaria, nesse sentido, como uma espécie de refúgio à violência desatada 
de seu tempo; e o fazer poético passa a ser visto como ação laboriosamente refletida e meditada.

Trabalhar o mito (no caso de "Abismo", o Minotauro, implicado no poema que a leitura articula à invasão de Creta por paraquedistas do exército fascista alemão) teria como decorrência, aqui, o despertar da figura mítica pelo moderno conflito bélico e (defende ainda Murilo Marcondes), o despertar também do poeta (a aceitação de sua convocação.) Acatando o convite, o poeta buscaria por sua vez transformar e não aceitar a realidade da guerra. Como entender isso? O caminho é ainda uma vez interno à estrutura, à forma. Trata-se de tomar o sonho (do qual o poeta despertara quando confrontado pelo conflito) e lançá-lo à realidade diurna, mantendo, "na realidade do dia, a liberdade noturna da atividade onírica”. A capacidade imaginativa do poeta, o trabalho com as imagens, com a palavra, prevê um espaço importante de liberdade - frente à Guerra. Citemos Murilo Marcondes, falando dos pontos comuns entre Henri Michaux, Murilo e os surrealistas (depois de os haver já distinguido): "Para ser muito sucinto, tratava-se de construir, contra a realidade, mas a partir dela, uma fantasia calculada ou um sonho provocado (baseados num 'furor lúcido'...)".

A citação ecoa de certo modo uma observação de Celan, transcrita por $\mathrm{Mu}^{-}$ rilo Marcondes logo no início de seu livro: “[...] o poema não está fora do tempo. Ele pretende certamente o infinito, mas ele busca passar através do tempo através, não acima". O modo como o poema atravessa o tempo (e o tempo de guerra), fazendo frente à realidade a partir do mergulho no concreto da história, é também o ponto perseguido, com ob- sessão meditada, por Murilo Marcondes de Moura.

\section{Referência}

MOURA, M. M. de. O mundo sitiado-A poesia brasileira e a Segunda Guerra Mundial. São Paulo: Editora 34, 2016.

Betina Bischof é professora do Departamento de Teoria Literária e Literatura Comparada da Faculdade de Filosofia, Letras e Ciências Humanas da USP.

@ - bbischof@usp.br

Recebido em 25.9.2017 e aceito em 17.10.2017.

I Departamento de Teoria Literária e Literatura Comparada, Faculdade de Filosofia, Letras e Ciências Humanas, Universidade de São Paulo, São Paulo, São Paulo, Brasil. 